\section{Noticia: arqueología y construcción. Una propuesta para la docencia técnica}

\author{
Miguel Ángel Tabales Rodríguez, Antonio Ramírez de Arellano Agudo \\ Dpto. Construcciones Arquitectónicas 2. \\ EUAT Universidad de Sevilla
}

\section{OBJETO}

Durante años se ha debatido en la Universidad sobre la necesidad de ofertar asignaturas dirigidas a la formación de los futuros arqueólogos con el fin de prepararlos para la vida profesional. Hay facultades donde se dieron pasos destinados a potenciar aspectos procedimentales o técnicos a la hora de formar no sólo investigadores, sino también técnicos capaces de resolver expedientes administrativos de urgencia, programas urbanísticos, etc... Un caso excepcional es el de la Universidad del País Vasco, en el que la disciplina de la Arqueología de la Arquitectura ha encontrado un espacio idóneo en el que desarrollarse dentro de un ambiente favorable de investigación.

Sin embargo, la realidad es que la mayoría de las facultades de Historia en las que se imparte la Arqueología, en general, parecen reacias a incorporar estudios tan específicos como los relativos a la arqueología del edificio debido, sobre todo, a la falta de comprensión sobre dicha disciplina por parte de los actuales responsables académicos, formados en su mayor parte en un período en el que las actividades de urgencia o los estudios de apoyo a la rehabilitación aún no se habían generalizado.

Esta evidencia, especialmente llamativa en ciudades y comunidades donde la actividad inmobiliaria vinculada a lo Patrimonial ha generado un considerable aumento de las perspectivas laborales de los arqueólogos en dicho campo, contrasta con el interés mostrado por las carreras Técnicas hacia todo aquello que afecta al estudio de lo construido.

En Sevilla, las Escuelas de Arquitectura Superior y de Arquitectura Técnica han incorporado en sus planes de estudios asignaturas relativas a la Arqueología de la Arquitectura con el fin de formar a los futuros aparejadores y arquitectos en unos contenidos indispensables para la comprensión del Patrimonio.

La Escuela Universitaria de Arquitectura Técnica imparte desde el curso 2003-2004 una asignatura cuatrimestral optativa de tercer curso denominada «Arqueología y Construcción» cuya misión es informar a los futuros aparejadores sobre la importancia del análisis arqueológico en la comprensión de los edificios históricos. La arqueología de urgencias, las cartas arqueológicas municipales, la economía de la intervención, la seguridad en excavaciones forman parte de un temario aún abierto pero de momento bien aceptado por los futuros agentes patrimoniales.

Se ha iniciado un experimento a nuestro juicio positivo, pero probablemente controvertido pues en algunos campos podría poner en evidencia las carencias de formación al respecto de gran parte de los arqueólogos actuales. 


\section{PERSPECTIVAS FORMATIVAS}

Las actuaciones de construcción desarrolladas en entornos vinculados, en mayor o menor grado, con yacimientos arqueológicos se ubican en un área del sector productivo de la industria de la construcción que da forma a un mercado claramente identificado y creciente.

Hoy es una evidencia que tanto las administraciones públicas como los promotores privados dedican cada vez mayores cantidades de recursos a la financiación de intervenciones en este segmento del sector, lo que da lugar a obras cada vez más complejas de mayor dimensión, que pueden ser de tipología muy diversa: recuperaciones de restos para ser expuestas en museos o en los propios yacimientos, restauraciones para conservar los restos encontrados y evitar nuevos deterioros, transformaciones de los entornos arquitectónicos (edificios o espacios) para ponerlos nuevamente en uso, etc. La complejidad y el elevado número de intervenciones ha aumentado de forma muy significativa la demanda de técnicos y especialistas cada vez más cualificados, hasta el punto en que en algunas áreas donde la densidad de yacimientos arqueológicos es alta (en Andalucía son muchas) los verdaderos especialistas empiezan a ser muy escasos.

Ante una situación como la que hemos descrito someramente, la Escuela de Aparejadores de Sevilla ha considerado de interés para los alumnos del Centro y para los Arquitectos Técnicos de su área de influencia, iniciar actuaciones para poner en marcha una línea curricular de formación especializada en la Arqueología de los Edificios, para dotar de mayores conocimientos en este campo, y de mayor sensibilidad frente a los problemas que proporcionan los edificios de carácter histórico o arqueológico, con el convencimiento de que cuanto más sepamos los aparejadores de estos temas, más útiles seremos a los arqueólogos, a los arquitectos $\mathrm{y}$, como consecuencia, a la sociedad a la que servimos.

Desde el punto de vista corporativo del colectivo de aparejadores y Arquitectos Técnicos, creemos que una participación más intensa de nuestros profesionales en la Arqueología Edilicia sólo puede generar efectos positivos en todos los agentes del sector, ya que no nos vemos como competidores de los Arqueólogos y de Arquitectos en los campos que les son propios, si no como colaboradores de ambos, aportando conocimientos específicos que pueden ser de gran ayuda en la toma de decisiones, en el desarrollo de los procesos constructivos y en la aplicación de las medidas de Prevención de Riesgos Laborales, que deben garantizar las seguridad de todos los agentes que participan en la doble actividad arqueológica y constructora.

Finalmente, parece conveniente hacer una breve referencia a que, después de un año de experiencia en la im- partición en nuestro Centro de la Asignatura optativa Arqueología y Construcción, y de analizar en este tiempo la participación de aparejadores en obras de carácter monumental de nuestro entorno más próximo como: el Hospital de las Cinco Llagas, el Real Alcázar de Sevilla, la Iglesia del Salvador, etc., las expectativas inicialmente creadas parece que se confirman, lo que nos estimula para seguir trabajando en esta línea.

\section{LA ASIGNATURA DE ARQUEOLOGÍA Y CONSTRUCCIÓN}

Se trata, por tanto, de una asignatura destinada a alumnos interesados en la rehabilitación arquitectónica desde cualquier óptica, tanto técnica como histórica. Su contenido pretende introducir al alumno en una de las partes esenciales del estudio previo a la recuperación de un edificio haciendo hincapié en los aspectos metodológicos y en la experiencia en rehabilitaciones del entorno. Se incide igualmente en los problemas derivados de las excavaciones arqueológicas urbanas (urgencias y emergencias), así como en la implicación del Arquitecto Técnico en dichas actividades en el marco de las nuevas normativas urbanas y reglamentos patrimoniales.

Por ahora los contenidos impartidos responden a las demandas más claras procedentes del ámbito de la rehabilitación. Falta tiempo de maduración y alguna experiencia docente para ir ajustando la disciplina a las necesidades formativas de los arquitectos técnicos, pero en cualquier caso, creemos que de momento se tratan los aspectos esenciales.

Como asignatura práctica la docencia teórica supone una tercera parte del total mientras que las actividades prácticas ocupan la mayor parte del tiempo asignado (un cuatrimestre). Los contenidos teóricos se dividen en cuatro unidades didácticas en las que se pretende aportar una visión general acerca de las distintas ramas o situaciones en las que la disciplina arqueológica confluye o interfiere con el ámbito de la construcción actual.

La primera de las unidades, introductoria, presenta la Arqueología desde un punto de vista evolutivo, incidiendo en las dos experiencias más ricas desde el campo de la metodología, como son la española y la italiana. Esta presentación es indispensable para que el alumno técnico comprenda una realidad compleja y multidisciplinar recientemente regulada, pero para la cual no ha sido preparado. La mayor parte de alumnos que cursan las carreras técnicas carecen de formación humanística y patrimonial por lo que tienden a simplificar un ámbito cognoscitivo que a menudo desprecian; sin embargo, dado que la legislación les atribuye grandes competencias y responsabilidades en campos como el de la rehabilitación, las escuelas han ido tomando conciencia de la necesidad de incidir algo más en estos aspectos. 
Un mejor conocimiento de la historia de la construcción, sobre todo del entorno en el que el futuro profesional va a desarrollar su labor, va a resolver parte de esas carencias. Estudios específicos sobre el comportamiento estructural de los edificios antiguos en restauración y sobre las técnicas de rehabilitación ya han sido incorporados a los planes de estudio. La Arqueología vinculada a los procesos constructivos se concibe bajo esta perspectiva como una optativa destinada a aquellos alumnos interesados en el Patrimonio que deseen comprender mejor las circunstancias que rigen los actuales procedimientos urbanísticos en ciudades históricas, entendiéndose Arqueología en sentido amplio.

Tras este primer bloque, el alumno debe haberse situado en una realidad muy compleja pero a la vez esperanzadora ya que además de abrir expectativas laborales hasta ese momento insospechadas va a tomar conciencia de cierto incremento cualitativo en su formación.

La primera parte mantiene un hilo argumental positivista en el que priman dos aspectos esenciales; el primero de ellos es la inexorabilidad del incremento de la presencia arqueológica en la rehabilitación de edificios y en el medio urbano. Los argumentos sociales, patrimoniales, históricos, etc...que han contribuido a generar dicho fenómeno en los países europeos más ricos en cuanto a su patrimonio histórico-arquitectónico (España, Italia, Francia) son analizados mediante una óptica evolutiva en la que se incide sobre los pasos y novedades que han ido configurando una nueva realidad todavía no asumida o conocida del todo por la sociedad.

El segundo argumento esgrimido es la necesidad de incremento del conocimiento sobre arqueología aplicada a este tipo de situaciones por parte, por supuesto de los arqueólogos y demás historiadores, y también de los futuros responsables en el campo de la arquitectura, tanto en las parcelas de proyección como en las de ejecución.

La segunda unidad didáctica introduce a los alumnos en la Arqueología del Edificio desde la perspectiva metodológica. Con ella se pretende aportar una idea básica de los procedimientos empleados en la documentación material de los edificios históricos, haciendo especial hincapié en las distintas lecturas arqueológicas de paramentos. Una lección sobre estratigrafía muraria introduce al alumnado en el campo del análisis pormenorizado de la edificación permitiéndole valorar las distintas operaciones constructivas y con ello iniciándolo en una valoración subconsciente de su valor patrimonial. Otros estudios, de carácter analógico, referentes a las tipologías edilicias, proporcionan una herramienta válida a la hora de identificar las técnicas habituales de nuestro entorno constructivo e histórico. Por último, se integra una parte del tradicional análisis de patologías desde la óptica del conocimiento histórico de la transformación de la fábrica. Con todo ello el futuro arquitecto técnico o arquitecto complementará la visión tecnológica del inmueble a través de una serie de valores, hasta ese momento identificados de manera vaga, poco comprensibles, y por tanto prescindibles.

La excavación arqueológica, sus fundamentos científicos, sus variedades metodológicas, los equipos interdisciplinares habituales y las peculiaridades del subsuelo en las edificaciones históricas completan una visión somera pero completa de la disciplina.

La metodología de la intervención en edificios históricos ha sido una asignatura tratada tradicionalmente en nuestra universidad, bien sea a través de su presencia en Masters de Arquitectura y Patrimonio como en asignaturas de libre configuración de nuestra escuela. Su conocimiento, limitado a los especialistas en rehabilitación se abre ahora a todos aquellos que sienten interés por los procedimientos de análisis implicados en obras de recuperación de edificios.

A pesar de que se trata de un bloque aparentemente específico de la disciplina arqueológica, su tratamiento informativo permite un acercamiento claro a las estrategias de investigación sin que eso conlleve intromisiones disciplinares. Una cosa es que el futuro jefe de obras de una rehabilitación sepa leer un documento arqueológico en el que se presentan diagramas estratigráficos o se sintetizan fases constructivas, y otras que pudiera dedicarse a efectuar análisis arqueológicos atribuidos competencialmente a otros profesionales.

La tercera unidad didáctica pretende introducir al alumno en aspectos vinculados de manera muy directa con su futura actividad profesional. Inicialmente se facilitan los fundamentos legales que condicionan la labor constructiva dentro de un tema en el que se explica cómo se han formado las necesidades actuales y de qué manera la nueva situación ha condicionado los planteamientos tradicionales de obra.

Tal vez la principal aportación de la nueva arqueología urbana sea la representada por las denominadas «Cartas Arqueológicas Municipales», impulsadas en nuestro territorio por la Consejería de Cultura de la Junta de Andalucía basándose en modelos italianos previos. La denominada "Carta del Riesgo del Patrimonio Cultural de Italia», de 1992, se ha erigido en modelo de nuestras cartas municipales, estableciendo un conjunto de acciones destinadas a identificar y evaluar el patrimonio histórico-arqueológico de ámbito municipal en su estado de conservación actual, diagnosticando las actuaciones que inciden 
sobre su conservación, programando y normalizando su protección a través de diferentes herramientas legales y, finalmente, programando su investigación, difusión y puesta en valor.

Entre los múltiples objetivos de las cartas municipales se encuentra el dar cabida a cualquier tipo de investigación que aporte datos sobre la conformación histórica de los yacimientos, sin discriminación de disciplinas ni metodologías, planteando análisis que van desde la escala particular a la general teniendo como referencia el territorio en el que se encuadran. Se pretende identificar variables o factores de afección y desafección que inciden en el patrimonio arqueológico: definición de impactos positivos y negativos a través del análisis de la normativa vigente, territorial, medioambiental, urbanística, etc...

La consecuencia práctica de estos planteamientos no es otra que la delimitación de ámbitos y niveles de protección. Una vez identificada la secuencia histórica del territorio y delimitadas las áreas, se identifican ámbitos de dimensiones variables, que van desde la parcela hasta áreas más extensas. Se trata de definir sectores donde aplicar las herramientas y cautelas de protección más oportunas. El establecimiento de "grados o cautelas» de intervención obliga a propietarios, promotores y constructores a resolver expedientes arqueológicos previos a la obtención de licencias de obra o a controles de movimientos de tierra o de obras en general que hasta hace poco podrían haber sido considerados como ingerencias poco razonables de la administración. Se trata de un hecho consolidado conceptualmente en el urbanismo actual de las ciudades históricas que conviene entender y en cualquier caso asumir.

Una parte esencial de este bloque informativo es el que presenta las novedades que a nivel de gestión desarrollan las administraciones vinculadas con la tutela del patrimonio histórico. Se atiende en especial al protocolo de estudios previos puesto en marcha por la Dirección General de Bienes Culturales mediante el cual se especifican los pasos obligatorios a cumplimentar con carácter previo a la redacción de los proyectos de restauración de inmuebles.

Ambas cuestiones, las cartas arqueológicas municipales y los procedimientos arqueológicos vinculados a las obras de rehabilitación, se configuran como las principales realidades en las que se hace imprescindible una formación actualizada para técnicos en construcción, y no sólo desde la perspectiva cultural, sino también profesional.

Y en esa línea, la profesional, se enmarcan los dos últimos temas de esta tercera unidad. La seguridad en investigaciones arqueológicas y las previsiones, mediciones y presupuestos se tratan tanto a nivel teórico como en prácticas específicas destinadas a familiarizar a los futuros arquitectos y arquitectos técnicos con situaciones cada vez más cotidianas pero aún no sistematizadas.

En el bloque de conceptos asignados a estos temas se intenta iniciar al alumno en el conocimiento de las singularidades de las actuaciones en los entornos arqueológicos desde el punto de vista de la Prevención de Riesgos Laborales, y en relación con las necesarias adaptaciones en los modelos de presupuestación que en su concepción actual no dan respuesta adecuada a las características de estas obras.

La última unidad teórica del temario trata sobre las técnicas constructivas habituales en nuestro entorno histórico. Se aporta una visión rápida centrada en los períodos históricos más representados en nuestra arquitectura popular; es una visión complementaria a la que aporta la asignatura de Historia de la Construcción, lógicamente más general.

El carácter práctico de la asignatura se pone de manifiesto mediante la ejecución de tres prácticas en grupo y la visita a diversos edificios históricos en rehabilitación o excavaciones arqueológicas. Se trata de prácticas cuya finalidad es acercar al alumno a la realidad profesional y por tanto le obliga a localizar información, desplazarse físicamente a lugares en obra, discutir procedimientos y finalmente generar documentos descriptivos, pero ante todo críticos. Es por tanto un esfuerzo intelectual prolongado que desemboca en trabajos que dan sentido al aparato teórico previamente asimilado.

La primera práctica consiste en el análisis arqueológico de un paramento o pequeño edificio bajo tres ópticas diferentes: estratigráfica, tipológica y constructiva, sintetizadas en un informe final sintético. Como es lógico no se pretende otra cosa que familiarizar al técnico con lenguajes y sistemas cada vez más extendidos en el ámbito de la rehabilitación y el urbanismo, acercándolo a una realidad material cuyo estudio contribuye a generar un respeto por las fábricas y técnicas antiguas probablemente inexistente o muy matizado previamente.

La segunda práctica consiste en un estudio de seguridad laboral y planificación de una obra en la que el componente arqueológico sea determinante. Con ella se pretende que los alumnos se enfrenten a una situación conocida y de plena actualidad; hasta ahora las grandes intervenciones en el Parlamento de Andalucía y en el Real Alcázar de Sevilla han sido objeto de estudios detallados.

Por último, la tercera práctica consiste en una revisión de la asignatura mediante el análisis global de un aspecto que haya cobrado un mayor valor a lo largo del curso. Además de repasar los conceptos generales de la asignatura este último esfuerzo sirve para afianzar técnicas de divulgación y puesta en valor patrimonial. 


\section{SIINTESIS}

Tras la conclusión de los cuatro cursos impartidos se puede considerar que la experiencia ha sido muy satisfactoria. En este período hemos tenido oportunidad de corregir algunas deficiencias en el planteamiento inicial y comprobar que la aceptación y el interés de los alumnos ha sido elevado, lo que nos anima para afrontar los desafíos que nos propone el nuevo Espacio Europeo de Educación Superior, donde intentaremos dar la mayor importancia a la formación de los futuros titulados en el campo de la intervención sobre edificios históricos. 